v. 01, n. 02 : pp. $033-042,2005$

ISSN 1808-0448

D.O.I.: $10.3895 / \mathrm{S} 1808-04482005000200003$
Revista Gestão Industrial

\title{
O CUSTO DE CAPITAL COMO TAXA MÍNIMA DE ATRATIVIDADE NA AVALIAÇÃO DE PROJETOS DE INVESTIMENTO
}

\section{THE CAPITAL COST AS MINIMUM INTEREST RATE IN PROJECTS INVESTMENT ANALYSIS}

\author{
Jocimari Tres Schroeder ${ }^{1}$; Ivanir Schroeder ${ }^{2}$; Reinaldo Pacheco da Costa ${ }^{3}$; Carlos Shinoda ${ }^{4}$ \\ ${ }^{1}$ UNIVALI; jocimari@matrix.com.br \\ ${ }^{2}$ POLI-USP / UNIVALI; ivanir.schroeder@poli.usp.br \\ ${ }^{3}$ POLI-USP; rpcosta@usp.br \\ ${ }^{4}$ POLI-USP; shinoda@inpg.com.br
}

Recebido para publicação em: 15/12/2004 Aceito para publicação em: 30/05/2005

\section{RESUMO}

Este trabalho tem como objetivo central analisar o custo de capital como taxa mínima de atratividade na avaliação de projetos de investimento. Destaca-se no arcabouço teórico, a estratégia da estrutura de capital das firmas, os critérios quantitativos utilizados na análise de projetos de investimento, bem como o custo de capital, e o custo médio e marginal de capital ponderado. Ainda complementando, apresentam-se razões e limitações no uso do custo de capital como taxa mínima de atratividade. Posteriormente, por meio de uma pesquisa empírica com firmas selecionadas, buscou-se conhecer as suas fontes de financiamento e as possíveis implicações do custo de capital como taxa mínima de atratividade na avaliação de projetos de investimento.

Palavras-chave: Custo de capital, Taxa mínima de atratividade, Projetos de investimentos.

\section{Introdução}

A exigência básica de um projeto de investimento é a geração de retorno econômico, que compense os riscos e os custos de capital envolvidos no investimento. As decisões de investimento e financiamento de um projeto de investimento podem ser separáveis, mas dificilmente podem ser independentes. O capital é um fator de produção, e como os outros fatores, tem seu custo associado.

As firmas necessitam conhecer as possibilidades de financiamento de seus projetos, pois assim conhecerão também o retorno (custo para firma) exigido pelos capitais disponíveis. Esse retorno exigido pelos capitais disponíveis, necessariamente deve ser considerado na avaliação de projetos de investimento. O retorno ou taxa exigida pelos capitais, representa o elo da ligação entre as decisões de investimento e financiamento dos projetos. 
O retorno exigido pelos fornecedores de capital, ou o custo de capital, pode ser utilizado como a Taxa Mínima de Atratividade (TMA) nas análises de projetos de investimento. Este artigo tem como objetivo central, analisar os benefícios e também as limitações do custo de capital como TMA. Para alcançar tal objetivo, dividiu-se o artigo em duas partes.

Na primeira parte destaca-se o arcabouço teórico (seções 2, 3 e 4) que oferece sustentação para uma pesquisa empírica. Na segunda parte, (seções 5 e 6) apresenta-se a metodologia e os resultados da pesquisa empírica, realizada para conhecer as fontes de financiamento utilizadas pelas firmas componentes da amostra selecionada.

\section{Estrutura de capital e taxa mínima de atratividade na decisão de investimentos}

A determinação da melhor estrutura ou a melhor combinação de fornecedores de capitais é importante e pode contribuir para a melhoria do resultado da firma. Modigliani \& Miller (1958), foram os pioneiros no exame de uma estrutura ótima de capital, conhecida como a proposição de M\&M. Esta proposição estabeleceu um tradeoff entre os custos e os benefícios do endividamento. Várias implicações práticas e teóricas, como também várias críticas foram e são feitas à proposição de $M \& M$.

Contrastando com o tradeoff entre os custos e benefícios do endividamento, Myers (1984), levantou que as firmas adotam a denominada teoria da hierarquização das fontes de financiamento (the pecking order theory). De acordo com esta, as firmas preferem a seguinte ordem de financiamento: recursos próprios (lucros retidos), endividamento e, por último, a emissão de ações.

A pecking order theory baseia-se na idéia de assimetria de informações entre a firma e o mercado. Esta assimetria ocorre porque o mercado não tem informações que a firma dispõe na tomada de decisões de projetos de investimentos. Assim, novas ações emitidas pela firma poderiam ser subavaliadas pelo mercado

De forma a entender como as firmas determinam sua estrutura de capital, Harris \& Raviv (1991) identificaram quatro categorias ou modelos estratégicos na determinação da estrutura de capital de uma firma. Uma estratégia de estrutura de capital seria a que possibilitasse a minimização dos custos de agência (conflito de interesses entre acionistas e executivos).

Outra estratégia seria a de minimizar a assimetria de informações entre a firma e os investidores em ações, preferindo a firma optar pelo autofinanciamento com recursos retidos, em seguida pelo endividamento, e finalmente pela emissão de ações (the pecking order theory). A terceira estatégia estaria ligada ao desejo da firma de influenciar a natureza dos seus insumos ou produtos no mercado competitivo; nesta estratégia admite-se que o endividamento da firma pode influenciar as reações com os clientes, fornecedores ou competidores. E, a quarta estratégia de 
estrutura de capital, concentra-se na possibilidade de influenciar o controle societário da firma.

A determinação da estrutura ótima de capital é conhecida como um verdadeiro quebracabeças na literatura financeira, e tem evidentes implicações na utilização do custo de capital para a decisão de projetos de investimento. Considera-se que dois métodos ou critérios são bastante recomendados e utilizados na análise de projetos de investimentos: o método do Valor Presente Líquido (VPL) e o método da Taxa Interna de Retorno (TIR).

O VPL e a TIR são considerados e denominados em grande parte da literatura financeira como os métodos mais tradicionais e eficientes na avaliação de projetos de investimentos. Além destes dois métodos, o critério de Período de Payback (PB) também é bastante utilizado, em grande parte, devido ao seu processamento simples. Eid (1996), analisou as técnicas de análise de investimentos utilizadas pelas firmas brasileiras e concluiu que 52\% das empresas fazem uso da TIR em algum momento, contra 51\% que utilizam o PB e $41 \%$ o VPL.

Os critérios do VPL e da TIR baseiam-se em fluxos de caixa descontados a uma determinada taxa. Esta taxa é denominada de TMA, ou seja, o retorno mínimo exigido para o projeto de investimento. Assim, quando a TIR de um projeto for superior a TMA, o projeto deveria ser aceito, pois, além de superar os custos do projeto de investimento e pagar o custo de capital, um possível remanescente da taxa adicionaria valor à firma.

A TMA é uma taxa que pode ser definida de acordo com a política de cada empresa. No entanto, a determinação ou escolha da TMA é de grande importância na decisão de alocação de recursos nos projetos de investimento. Para Galesne; Fensterseifer \& Lamb (1999), a taxa de desconto, ou a TMA mais apropriada para decisões de investimento é a taxa do custo de capital.

Gitman (2001) considera o custo de capital como o retorno exigido pelos financiadores de capital para a firma, e, portanto, a TMA que a firma deveria considerar em seus projetos de investimento. Assim, um projeto de investimento necessariamente é interessante quando atender seus fornecedores de capital e adicionar valor à firma, remetendo ao conceito do EVA (Economic Value Added).

As firmas podem se financiar por meio de capital de terceiros (endividamento), capital próprio (emissão de novas ações ordinárias e/ou preferenciais), e de reinvestimento de lucros, retendo parte ou todo dos dividendos devidos aos acionistas (retenção de lucros). Cada uma destas fontes de financiamento tem um custo específico para a firma, conhecido como o custo de capital, que reflete as expectativas de retorno de longo prazo dos financiadores.

Considera-se que o custo de capital é, portanto, a TMA mais apropriada para a avaliação de novos projetos de investimento da firma. Se os fornecedores de capital tomaram a decisão de financiar a empresa em dado momento por um custo de capital, com expectativas de retorno no longo prazo, então, este mesmo custo de capital pode ser uma referência - a TMA, para a avaliação 
de novos investimentos. Portanto, a TMA referenciada no custo de capital da firma, pode servir como determinante na aceitação ou não de novos projetos de investimento, adicionando também valor à firma.

\section{3. $O$ custo de capital médio ponderado}

Um critério importante de custo de capital e que pode ser utilizado como TMA, é o custo médio ponderado de capital (CmePC), que reflete a política global de utilização de diferentes capitais no financiamento da firma. $\mathrm{O} \mathrm{CmePC}$, pode ser obtido pela ponderação do custo de cada fonte de financiamento $(\mathrm{K})$, pela sua sua proporção na participação no capital global da empresa (W), refletindo a política da estrutura de capital da firma.

Onde:

$$
\mathrm{CmePC}=\left(\mathrm{W}_{\mathrm{d}} \times \mathrm{K}_{\mathrm{d}}\right)+\left(\mathrm{W}_{\mathrm{p}} \times \mathrm{K}_{\mathrm{p}}\right)+\left(\mathrm{W}_{\mathrm{o}} \times \mathrm{K}_{\mathrm{o}}\right)+\left(\mathrm{W}_{\mathrm{lr}} \times \mathrm{K}_{\mathrm{lr}}\right)
$$

$\mathrm{W}_{\mathrm{d}=\text { proporção da dívida. }}$

$\mathrm{W}_{\mathrm{p}}=$ proporção das ações preferenciais

$\mathrm{W}_{\mathrm{o}}=$ proporção das ações ordinárias

$\mathrm{W}_{\mathrm{lr}}=$ proporção dos lucros retidos

Como salientado anteriormente, cada fonte de financiamento da firma (capital de terceiros -dívida; capital próprio - emissão de ações, e reinvestimento - lucros retidos) requer uma taxa de retorno mímina, implicando um custo específico para a firma. O custo do capital de terceiros é representado pelos juros exigidos; o custo do capital próprio é o valor referente ao pagamento dos dividendos esperados/exigidos pelos acionistas; e o custo do reinvestimento é igual ao custo do capital próprio. Esta igualdade se explica pelo princípio do custo de oportunidade, uma vez que a retenção do lucro significa um não recebimento de dividendos por parte dos acionistas, que poderiam destinar estes dividendos recebidos para outros investimentos (WESTON \& BRIGHAM,2000).

À medida que a firma necessite investir e aumentar o volume de financiamento, os custos de suas fontes de financiamento tenderão a se elevar, afetando o CmePC e, consequentemente refletindo na tomada de decisão da análise de projetos de investimento. Gitman (2001, p. 355) argumenta que "aumentos nos custos dos componentes de financiamento ocorrem porque quanto maior o montante de novo financiamento, tanto maior o risco para o fornecedor de fundos. [...] fornecedores de fundos exigem maiores retornos $[\ldots]$ ".

Assim, torna-se importante calcular e analisar o custo marginal ponderado de capital (CmaPC) e identificar os pontos de ruptura no CmePC. Segundo Weston \& Brigham (2000), o CmaPC é a variação no CmePC para cada \$1 de capital novo obtido pela firma. Já o ponto de ruptura é identificado pelo valor do capital novo que pode ser obtido antes que ocorra o aumento no 
CmePC da firma. Desta forma, o ponto de ruptura marca um limite para a decisão de tomada de novos investimentos e financiamentos.

Porém, a utilização do custo de capital e, especialmente do CmePC, como TMA na avaliação de projetos de investimento, suscita limitações importantes ou no mínimo, remete a reflexão de algumas questões específicas. Discutir e analisar as limitações da utilização de uma determinada TMA na análise de projetos de investimento pode evitar falácias que podem gerar, ao longo do tempo, a perda de valor econômico para os acionistas.

\section{Limitações do custo de capital como TMA}

$\mathrm{Na}$ análise da viabilidade de um projeto de investimento muitas variáveis precisam ser consideradas. Dentre estas variáveis pode-se mencionar a estratégia da firma, suas políticas, a estrutura de mercado em que está inserida, seus pontos fortes e fracos, bem como possíveis ameaças ao seu negócio. Enfim, fatores endógenos e exógenos, positivos e negativos, que influenciam a sobrevivência da firma e a geração de valor para seus acionistas ou proprietários.

Além destas variáveis, a engenharia econômica se utiliza de métodos quantitativos importantes para aceitar ou rejeitar projetos de investimento. A escolha do método e da TMA na análise de projetos de investimento é essencial, não somente para o sucesso de determinado investimento, mas para o sucesso da firma. Assim, pode-se relacionar algumas questões que deveriam ser consideradas ao se adotar o custo de capital como a TMA na análise de projetos de investimentos:

- Firmas com mais de um négocio, podem ter mais dificuldades ao se utilizarem do CmePC global, talvez o mais indicado, seria o CmePC do negócio específico.

- Utilizando-se o CmePC global para a análise de projetos de investimento, torna-se importante considerar os riscos ajustados a cada projeto, sob a pena de rejeitar ou aceitar projetos inadequados ou importantes para a firma.

- O denominado custo de agência (conflito de interesses entre acionistas e executivos), pode estar presente na tomada de decisão de projetos de investimento, pois os executivos podem ser levados a optar por projetos de menor risco. Essa decisão pode ser apoiada em um custo de capital utilizado de forma inaproriado.

- Limitações para identificar e mensurar o custo de capital.

- Considerar preços ou valores contábeis na mensuração do custo de capital da firma pode ser mais uma dificuldade, pois a dinâmica das análises de projetos de investimento pressupõe que o analista atribua preços ou valores de mercado, atualizando fatos passados.

- A definição de uma estrutura ótima ou alvo de capital, por estratégia da firma, pode ser 
importante e precisa ser considerada ao se aceitar ou rejeitar projetos de investimento, que naturalmente levarão a novos financiamentos e a readequação da estrutura de capital da firma.

Anderson; Byers \& Groth (2000) defendem o uso do custo de capital como TMA. Dentre as várias justificativas, os autores acreditam que os gerentes são eficazes o suficiente para eliminar o risco desnecessário, e o custo de capital da firma refletiria o risco aceitável para as fontes financiadoras. Os autores ainda advertem que os gerentes ao aceitarem projetos de maior risco, por admitirem informações assimétricas entre a firma e o mercado, podem comprometer a credibilidade tanto dos próprios gerentes como da firma. Além disso, uma gerência que desenvolva algum tipo de relacionamento emocional com o projeto de investimento, pode utilizar uma TMA menor, de modo a justificar a aceitação do investimento.

Acredita-se que, apesar de suas limitações, o custo de capital pode ser a melhor opção como TMA na avaliação de projetos de investimento. Assim, independentemente da estatégia da empresa na determinação de sua estrutura de capital, o analista pode apoiar-se nesta estrutura para obter o custo de capital como TMA. Nas duas próximas seções apresenta-se uma pesquisa empírica realizada para conhecer a estrutura de capital de firmas selecionadas.

\section{Metodologia da pesquisa}

Com o objetivo de conhecer a participação das fontes de financiamento, foi realizada uma pesquisa com 11 firmas, que tiveram o maior volume de negociações na Bolsa de Valores de São Paulo (Bovespa), no período 2001/2003, após as significativas transações de fusões e aquisições no Brasil. A seleção da amostra intencional foi estabelecida basicamente por dois motivos.

O primeiro motivo refere-se a facilidade de obtenção de dados secundários, por se tratarem de firmas de capital aberto. O outro motivo está relacionado com a grande concentração de negociações no mercado secundário de ações brasileiro, o que acaba dificultando o financiamento das firmas por meio de emissão de novas ações. Cabe salientar que o mercado secundário de ações brasileiro apresenta uma elevada concentração de negociações em um restrito número de firmas.

Em média no período 2001/2003, 400 firmas estavam listadas na Bovespa. A escolha das 11 firmas analisadas por esta pesquisa levou em consideração que estas foram responsáveis em 2001 por 53,85\% dos negócios diários na Bovespa, em 2002 por 56,51\%, e, em 2003 por 53,50\%. As firmas da amostra selecionada, se distribuem entre 6 setores: telecomunicação (4), petróleo (1), mineração (1), banco (2), energia elétrica (2) e siderurgia (1).

Optou-se por analisar o período 2001/2003, considerado posterior a uma década de grandes fusões e aquisições no Brasil e no mundo. As fusões e aquisições provocam alguns distúrbios na estrutura de capital, podendo distorcer as análises. 
Durante a década de 1990, o fluxo de Investimento Direto Externo (IDE) mundial foi intenso. No Brasil o IDE se intensificou devido as inúmeras fusões e aquisições, que ganharam impulso por meio das privatizações de empresas estatais. Segundo Siffert Filho \& Silva (2004), a estimativa é que o valor das fusões e aquisições no Brasil, somente no período 1991-1998, tenha sido da ordem de US\$ 142 bilhões, incluindo as privatizações, que responderam por 51,7\% desse total.

Adotou-se o modelo de Singh (1995) como método de estimação da estrutura de capital das firmas selecionadas, obtendo-se o percentual de participação das fontes de capital no financiamento. Esse modelo utiliza dados secundários, obtidos dos balanços anuais das firmas, e estima os lucros retidos, o capital de terceiros e o capital próprio, que são obtidos pelas fórmulas a seguir detalhadas. A consulta dos balanços anuais foi realizada por meio do banco de dados dos balanços e informações anuais, disponíveis no site da Bovespa.

Lucros Retidos $=$ (lucro líquido - dividendos pagos $) /($ ativo total - passivo circulante $)$

Capital de Terceiros $=($ passivo longo prazo $) /($ ativo total - passivo circulante $)$

Capital Próprio $=1-($ Lucros Retidos + Capital de Terceiros $)$

Foram aplicadas as fórmulas para cada firma, e posteriormente, calculadas as médias ponderadas, por ano e para o período 2001/2003, para o conjunto da amostra.

\section{Resultados da pesquisa}

Os resultados obtidos apontam para evidências de que as firmas utilizaram com ênfase acentuada fontes de capital de terceiros para financiar seus investimentos. Somente no ano de 2001 as fontes de capital próprio foram mais elevadas do que a fonte de capital de terceiros. Em 2001, uma firma da amostra realizou modificações na estrutura de seu capital societário, por meio de incorporações de outras controladas, o que explica algum distúrbio e diferença entre as fontes de capital neste ano. A Figura 1 apresenta os resultados encontrados por ano, no período 2001-2003.

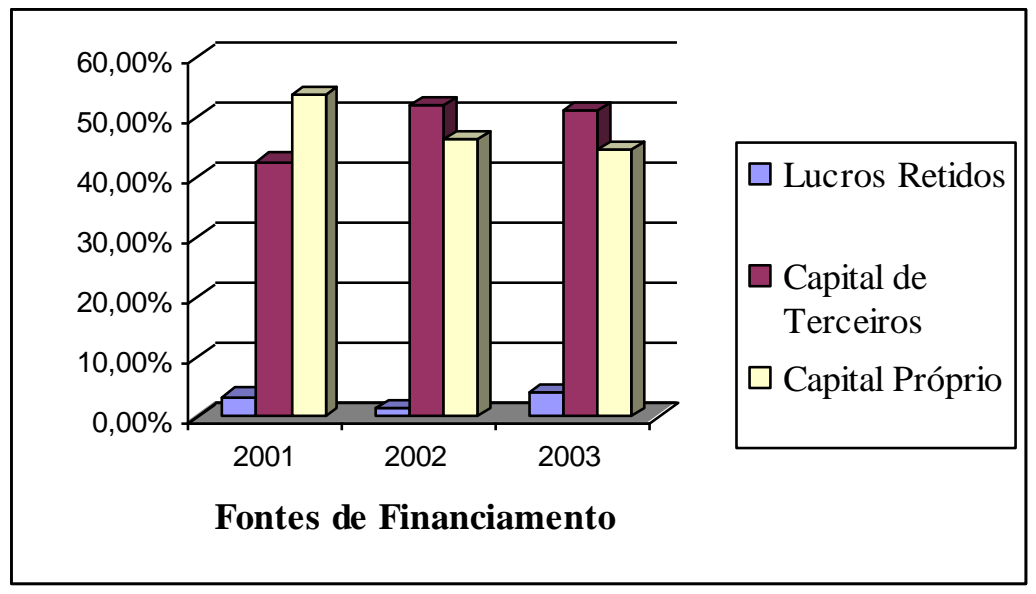


Fonte: elaborada pelos autores

Figura 1 - Padrão de financiamento por ano

Singh (1995) concluiu que os países em desenvolvimento utilizam mais fontes externas, em especial a emissão de ações (capital próprio). Porém, o que se verificou é que excetuando-se o ano de 2001, os anos de 2002 e 2003 apresentam uma maior utilização das fontes de capital de terceiros para o financiamento das firmas. O que pode explicar tal situação é a característica do mercado de ações brasileiro, que apresenta poucas emissões primárias de ações.

Outro fato que poderia explicar tal situação, está na hipótese de que estas firmas, consideradas de primeira linha, possuem mais facilidades de captar recursos no exterior, a juros mais atrativos, quando comparados com os praticados no mercado interno. Desta forma, conseguiriram ganhos significativos em operações de arbitragem, com os juros praticados no mercado interno. Além disso, não se evidenciou nos anos de 2001, 2002 e 2003 a teoria da hierarquização das fontes de financiamento (the pecking order theory).

Os resultados do período 2001/2003, para o total da amostra, continuam evidenciando a utilização das fontes externas como financiamento, em especial os recursos de terceiros (49,2\%), contra capital próprio $(47,7 \%)$ e lucros retidos $(3,1 \%)$. Também não se constatou para o total do período a the pecking order theory.

Quando se verifica os resultados obtidos, acredita-se que a utilização do custo de capital, em especial do $\mathrm{CmeCP}$, é justificada. A estrutura de capital das firmas analisadas utiliza mais significativamente fontes externas de financiamento (em especial, de capital de terceiros), e, estas precisam de uma referência para continuar a financiar tais firmas, minimizando a assimetria de informações. A utilização de taxas ajustadas, ou diferentes do custo de capital, podem prejudicar a confiança nas decisões da firma, dificultando o financiamento de seus projetos.

\section{Considerações finais}

Para uma eficaz tomada de decisão na análise de projetos de investimento é necessária a apropriada seleção da TMA. A importância de uma TMA deve-se ao fato desta atuar como o elo de ligação entre a decisão de investir e a de financiamento. As fontes de financiamento da firma desejam um retorno econômico satisfatório sobre os projetos de investimento. Ou seja, um retorno que além de cobrir os custos do investimento, tenha um remanescente que adicione valor à firma.

Acredita-se que a formação da estrutura de capital de uma firma não é uma decisão unilateral. As fontes de financiamento (componentes da estrutura de capital), precisam ser convencidas da validade, do retorno satisfatório, dos projetos de investimento da firma. Além disso, 
a firma tende a buscar uma estrutura ótima ou uma estrutura-meta de capital, ou seja, aquela que possa agregar mais valor, com o menor custo de capital.

Apesar das limitações da utilização do custo de capital como TMA na análise de projetos de investimento, acredita-se que o custo de capital ainda é o critério mais aceitável e justo. Trata-se de um critério mais objetivo e transparente, evitando-se direcionamentos ou justificativas de determinados projetos pelos quais os gerentes estejam mais inclinados a aceitar ou rejeitar, por motivos políticos. Considera-se também que utilização do custo de capital permitiria minimizar os custos de agência.

A pesquisa empírica demonstrou que no período 2001/2003 as firmas utilizaram mais capital de terceiros como fonte de seus financiamentos. Esta constatação reforça a viabilidade da utilização do custo de capital como TMA para analisar projetos de investimentos, uma vez que pode gerar confiança nas fontes de financiamento das firmas.

No entanto, alguns fatores como a simplificação da amostra e o método de estimação da estrutura de capital, utilizados na construção deste artigo, permite ainda a possibilidade de refinar esta metodologia com intuito de ampliar a análise. Porém, acredita-se que a metodologia utilizada cumpre seu objetivo quanto aos critérios científicos e apresenta coerência com as teorias de finanças e economia.

O tema central deste artigo, custo de capital como TMA na avaliação de projetos de investimento, faz parte de inúmeras discussões no meio acadêmico. Muitas vezes o assunto provoca refutações e críticas quanto aos meios utilizados na análise dos projetos de investimento, especialmente quanto à TMA utilizada. Considera-se ainda que a discussão é inerente à ciência, e que obviamente favorece a evolução do conhecimento. Assim, este tema ou assunto, comporta outros desdobramentos e pesquisas, o que acredita-se, irá colaborar com a sua contínua evolução.

\section{ABSTRACT}

This paper has like central objective analyzes the cost of capital as the minimum interest rate in projects investment evaluation. Detaches-itself in the theoretical framework, the strategy of the capital structure of the firms, the quantitative criteria utilized in the investment project analysis, as well the weighted average and marginal cost of capital. Complementing, we present reasons and limitations in the use of capital cost as the minimum rate of interest. Subsequently, by means of an empirical research with selected firms, sought itself know his sources of financing and the possible implications of the capital cost as minimum rate of interest in the investment projects evaluation.

Key Words: Capital cost, attractiveness rate of interest, Investment projects.

\section{Referências}


ANDERSON, R. C.; BYERS, S. S.; GROTH, J. C. The cost of capital for projects: conceptual and practical issues. Management Decision, v. 38, n. 6, p. 384, 2000.

\section{cross ${ }^{\text {ref }}$}

EID JÚNIOR, W. Custo e estrutura de capital: o comportamento das empresas brasileiras. Revista de Administração de Empresas, v. 36, n. 4, 1996.

GALESNE, A.; FENSTERSEIFER, J. E.; LAMB, R. Decisões de investimentos da empresa. São Paulo : Atlas. 1999.

GITMAN, L. J. Princípios de administração financeira. 2. ed. Porto Alegre : Bookman. 2001.

HARRIS, M.; RAVIV, A. Theory of capital structure. Journal of Finance, v. 46, n. 1, p. 297-355, 1991.

cross ref

MYERS, S. C. The capital sctruture Puzzle. The Journal of Finance. v. 39, n. 3, p. 575-592, 1984.

cross ${ }^{\text {ref }}$

MODIGLIANI, F.; MILLER, M. The cost of capital, corporation finance and the theory of investment. American Economic Review, v. 48, n. 3, p. 261-297, 1958.

SIFFERT FILHO, N.; SILVA, C. S. As grandes empresas nos anos 90: respostas estratégicas a um cenário de mudanças. Disponível em: <www.bndes.gov.br/conhecimento〉. Acesso em: 2004.

SINGH, A. Corporate financial patterns in industrializing economics: a comparative internacional study. Technical Paper - IFC. Disponível em: <www.ifc.com>. Acesso em: 2005.

WESTON, J. F.; BRIGHAM, E. F. Fundamentos da administração financeira. 10. ed. São Paulo : Makron Books, 2000. 